\title{
Veto do Presidente Epitácio Pessôa à Resolução do Congresso Nacional que fixa a Despesa para o Exercício de 1922
}

\section{INTRODUÇÃO}

ARY SEIXAS

\begin{abstract}
A
mensagem de Veto, que ora se reproduz, diz respeito, ùnicamente, à despesa orçamentária vctada para o exercício de 1922 , pois o projeto de orçamento dn receita fôra sancionado dias antes em consequiência do uso, iniciado pelo Decreto n. ${ }^{\circ} 2.887$, de 1879 , de votar o orçamento em dois projetos distintos.
\end{abstract}

Além de constituir fato até então inédito, entre nós, êsse veto do Presidente EPITÁcio PESSôA assumiu excepcional importância, na elaboração orçamentária brasileira, por ter conseguido desmoralizar em definitivo as célebres "caudas orçamentárias", menos pelo valor jurídico dos argumentos já incorpcrados à melhor doutrina - do que pelo vigoroso estilo do eminente paraibano, nêle, como em poucos, realmente o homem.

Exemplo eloqüente do que se afirma são, entre outros, os trechos das "razões do veto", em que ferreteia a cauda orçamentária, em seu duplo aspecto de majoração de despesa e de excrescência na lei de meios:

"O Congresso não se anima a decretar impostos na medida das despesas que autoriza e lança à responsabilidade do Presidente da República, que os não pode criar, o não cumprimento de uma lei em que a despesa sobrepuja a receita em mais de 360 mil contos!"

"As leis de orçamento entre nós têm sido profundamente deturpadas. Nela se insinuam disposições as mais estranhas e se acoitam os mais audaciosos interêsses pessoais, confiantes em que o Presidente da República os tolerará para não se privar dos meios de govêrno".

Diga-se, porém, a bem da verdade, que os enxertos nas leis de orçamento não eram da responsabilidade exclusiva do Congresso, como prova o parecer exarado pela Comissão Especial da Câmara dos Deputados (a Co- 
missão dos 21) sôbre c projeto de reforma da primeira Constituição Republicana:

... "também a função legislativa do Congresso se restringe, se não se anula de todo, pelas freqüentes autorizações e delegações que à última hora, apressadamente, às vêzes sem a menor explicação, se incluem nas leis de orçamento.

"Interêsses ocasionais, amparados por fôrças preponderantes, criam serviços, protegem empreendimentos, resolvem problemas importantes, por um simples e lacônico dispositivo incluído nessas leis. Por meio delas, e por êsse processo, a pressão da solidariedade política facilita ao Govêrno, em virtude das solicitações instantes dos Ministros, recurscs para novas e avultadas despesas, que destroem o equilíbrio trabalhosamente procurado no orçamento real, entre a receita e a despesa." (1)

Que êsse malsinado recurso também não era peculiar à prática parlamentar bresileira, provam-no os diversos nomes por que já o conheciam várics príses, como informa Carlos Maximiliano em seus Comentários à Constituição Brasileira: - Riders (Cavaleiros), entre os norte-americanos; Bepackung (empacotamento), para os alemães; e Tacks (prendedores), na Inglaterra.

Acrescente-se, ainda, que, embora desrespeitados na prática, o Regimento Interno do Senado (art. 142) e o da Câmara (art. 261) proibiam a apresentação de emendas com o caráter de proposições principais aos projetos de orçamento.

Tratava-se, portanto, de um abuso inveterado, cujas conseqüências não podiam ser derrubadas, nem mesmo pela nossa mais alta Côrte de Justiça, como se depreende dos dois acórdãos abaixo, reproduzidos parcialmente dia obra supracitada:

"A inserção, embora irregular, de disposições de caráter permanente em leis orçamentárias, não é motivo bastante para que sejam elas declaradas inaplicáveis pelo Pcder Judiciário, findo o ano para o qual foram votadas" (Acórdão do Supremo Tribunal Federal, n. ${ }^{\circ} 3.443$, de 25 de outubro de 1913, in Octavio Kelly Manual de Jurisprudência Federal, 1914, p. 229).

"Não procede o argumento que, sendo essa lei n. ${ }^{\circ} 2.719$ orçamentária e, como tal, ânua, não pade estender seus eleitos além do período de sua duração; porquanto, segundo a jurisprudência administrativa desde o tempo do Império e a judiciária seguida por êste Tribunal, em uma lei orçamentária se incluem disposições de

(1) Anais da Revisão Constitucional, vol. 1, p. 302-335. 
caráter permanente, o que pode não ser regular, mas é ccnsagrado, pela prática." (Acórdão unânime, do Supremo Tribunal Federal, proferido no Agravo n. ${ }^{0} 1.835$, a 29 de janeiro de 1915, in Revista do Supremo Tribunal, 1.915, vol. II, $1 .^{\mathrm{a}}$ parte, p. 466).

A luz dêsses antecedentes, que de propósito citamos para a justa aferição da grandeza de seu ato, não se pode dizer que o Presidente EPITÁcio PFssôA tenha sido excessivamente drástico, ao vetar, em sua totalidade, o orçamento da despesa para 1922, em que, segundo suas próprias palavras, havia de tudo: "reformas de repartições, regulamentos de natureza executiva, nomeações de funcionários públicos, injustiças clamorosas, favcres individuais de tôda casta, medidas evidentemente prejudiciais à Nação, disposições contraditćrias ou extravagantes".

De resto, a única alternativa possível, ou seja, o veto parcial - embora dêle se confessasse partidário o Presidente EpITÁcio PEssôA - revelava-se ineficaz, no caso, por não facultar a correção das tabelas erradas ou incompletas, além do que tinha contra si a opinião geral, pois ainda se não incorporara expressamente à Constituição, o que só ocorreu em 1926. Todos êsses motivos induziram o Presidente Epitácio PessôA a abster-se de usá-lo, ccnforme declarou, depois, na mensagem de convocação extraordinária do Congresso para deliberar sôbre seu ato, na qual frisa, ainda, que não tinha o direito, como Chefe de Estado, de tentar a adoção dos seus pontos de vista disutrinários sôbre o veto parcial, em momento de tal gravidade, nem devia abandonar a renovação de um projeto, que considerava verdadeira calamidade nacional, à preliminar aventurosa de uma discussão acadêmica.

O misto de arrôjo e de prudência, revelado pelo insigne estadista, ao optar pelo veto total, é na verdade indiscutível, pois, revolucionando as nossas tradições políticas, fazia-o, contudo, no sentido da exegese doutrinária e da jurisprudência construída em torna do texto da Constituição norte-americana, do qual era a nossa uma cópia quase fiel, no artigo que autorizava o veto presidencial, entre outros. A êste respeito é bastante elucidativo o trecho que recolhemos no parecer da Comissão de Constituição e Justiça da Câmara, sôbre o projeto de orçamento vetado (2), do qual foi relator o Dep. AFrÂnIo de Melo Franco, trecho traduzido de Willoughby (On the Constitution, vol. $1^{\circ}$, p. 569), sôbre a ccnduta do Executivo norte-americano em casos semelhantes:

"O Poder Executivo nunca tentou o exercício do direito de vetar parte das medidas a êle submetidas, pelo Congresso, e de aprovar o restante. Sendo êle obrigado a aceitar ou rejeitar os projetos em sua integralidade, $c$ Congresso tem tentado mais de uma vez forçar a mão do Presidente, incorporando, em medidas que de antemão se sabe ser êle quase obrigado a assinar, providências estra. nhas que provàvelmente seriam recusadas por êle, caso the fôssem

(2) In Diário do Congresso, de 22 de marçc de 1922, p. 76-83. 
apresentadas em proposições independentes. Muitas vêzes, entretanto, êsses chamados "riders" provocaram um "veto" do Projeto em sua totalidade, e outras vêzes o Presidente assinou os projetos, enviando ao Congresso uma mensagem de protesto." (grifamos).

Notável, como vimos, pelos antecedentes que o geraram, êste veto não nos foi menos pelas conseqüências dêle advindas, constituindo-se, assim, em verdadeiro marco, em função do qual se tem de referir a evolução dos orçamentos públicos no Brasil.

Mesmo se não se quiser atribuir o caráter de decorrência direta do veto em questão, aos preceitos sôbre elaboração orçamentária introduzidos com a reforma constitucional de 1926 , não há como negar que o veto de 1922 , tornando agudo o mal crônico das caudas orçamentárias, inspirou a providência suprema de consignar-se expressamente na Constituição o que, há tanto e sem resultado, proibiam os regimentos parlamentares.

Neste sentido, dois anos depois, encarecendo a necessidade da revisão constitucional, o Presidente ARTUR DA Silva BERnARdes sustentava, na mensagem apresentada ao Ccngresso quando da abertura da sessão legislativa de 1924:

"A garantia do equilíbrio orçamentário e a boa ordem nas finanças públicas é a primeira das condições para que a Nação possa viver e prosperar. "Sem preceitos constitucionais expressos e terminantes, que impeçam as denominadas "caudas orçamentárias", cancro dos orçamentos, que os corrói e os aniquila, nada de estável poderá ser obtido nas finanças públicas.

"Não há como esconder que os melhores propósitos para evitar êsse mal, que já é sediço e quase ridículo proclamar, nada conseguirão, se a Constituição não o proibir de modo insofismável, contra o natural pendor do menor esfôrço por parte do Poder Executivo e do Poder Legislativo, inclinados e habituados a resolver tôdas as questões nas caudas dos orçamentos."

E, mais adiante, procurando encontrar remédio contra o aspecto do volume da cauda orçamentária, também profligado pelo Presidente EPITÁcio PessôA e mais difícil de vencer:

"Por outro lado, a criação de despesas ordinárias, sem exame prévio das possibilidades de pagá-las ccm as receitas ordinárias, agrava a situação deficitária permanente, em que nos debatemos. "Urge sair dêsse impasse funesto ao futuro do país. A Constituição deve, pois, proibir também qualquer despesa ordinária, sem a criação da receita ordinária que the faça face e prescrever que às despesas extraordinárias correspondam recursos extraordinários, concomitantemente criados, sem esquecer que êsses recursos geram, por vêzes, encargos permanentes de juros e outros, que terão de figurar nos orçamentos." 
$\mathrm{Na}$ Assembléia Revisionista, embora contrariando opiniões prestigiosas, como a do Deputado SÁ FırHo, que afirmava - "... enquanto não se der volume e eficiência ao Poder Legislativo, a administração precisará de servir-se do expediente das caudas para poder trabalhar, pois difícil será conseguir das leis especiais, morosas sempre, as providências exigidas pelcs serviços púbiicos" (3) - a proibição de legislar no orçamento veio a ser assegırada, incorporando-se ao texto constitucional através do acréscimo do $\S 10^{\circ}$ ao artigo 34 (gênese do $\S 10^{\circ}$ do artigo 73 , da Constituição de 1946) e do $\S 34$ ao artigo 72 (hoje artigo $65, \mathrm{n}^{\circ}$ IV), do seguinte teor, respectivamente:

"Art. 34. Compete privativamente ao Congresso Nacional:

"§ $10^{\circ}$ As leis de orçamento não podem conter disposições estranhas à previsão da receita e à despesa fixada para os serviços anteriormente criados. Não se incluem nessa proibição:

a) a autorização para abertura de crédito como antecipação. da Receita;

b) a determinação do destino a dar ao saldo do exercício ou do mado de cobrir o "deficit".

"Art. 72 .

"§ 34. Nenhum emprêgo pode ser criado, nem vencimento algum, civil ou militar, pode ser estipulado senão por lei ordinária especial."

Todavia, não foi aprovada, nem mesmo em parte, a emenda que visava a evitar os inconvenientes das caudas tendentes a avolumar a despesa pública, emenda pela qual seria acrescentado, ac artigo 36 da Constituição, c seguinte:

"§ 2. Os projetos ou emendas criando ou aumentando despesa deverão também criar ou aumentar a receita correspondente.

“a) Não poderá ser administrativamente autorizada a despesa, sem que a respectiva receita tenha sido efetivamente arrecadada.

“b) Para os efeitos dêste parágrafo, o Senado pcoderá ter a iniciativa da criação ou aumento de receita."

Logo na primeira discussão, na Câmara dos Deputados, levantou-se contra essa emenda a voz do Deputado Adolfo Bergamini, (4) chamando a atenção de seus pares para doris aspectos:

$10^{\circ}$ o de que a mesma representava uma imposição estrangeira, pois teria constado do relatório da Missão de financistas britânicos presidida por

(3) Declaração de Voto - in Diário do Congresso, de 9-7-26, p. 1.169-1174.

(4) Discurso in Anais da Revisão Constitucional, vol. 1, p. 493-515. 
LORD MONTAGU, que, até dois meses antes de ser enviada ao Congresso a mensagem revisionista de maio de 1924, aqui estivera a convite do guvêrno brasileiro, estudando as nossas condições econômicas e financeiras e prescrevendo normas que, se fôssem seguidas, poderiam permitir o levantamento de capitais para o empréstimo de consolidação pretendido pelo Presidente ARTUR BERNARDES;

$2 .^{\circ}$ ) o de que a emenda levaria ao absurdo (sic) de, nos projetos originários do Senado, ficar aquela Casa do Poder Legislativo com c direito da iniciativa de criação de impostos, prerrogativa que, na opinião do orador, deveria continuar a ser da competência exclusiva da Câmara, sob pena de atentar-se contra cs princípios do regime democrático.

Quanto a êste segundo aspecto - importante, sem dúvida - não passara despercebido à Comissão dos 21 da Câmara dos Deputados, que assinalara em seu parecer constituir o mesmo decorrência da adoção da primeira parte da emenda, pois, passando-se a exigir, simultâneamente $\mathrm{ccm}$ a criação ou aumento da despesa, a criação ou majoração da receita a ela correspondente, a manutenção da iniciativa exclusiva da Câmara para criar ou aumentar receita, equivaleria a despojar o Senado do seu direito de propor a instituição de serviços e autcrização de despesas.

Pesando as vantagens e os inconvenientes das medidas contidas na referida emenda, a dita Comissão concluira pela sua aceitação, frisando:

"O seu dispositivo não permite que representantes da Nação, menos escrupulosos em propor aumento de despesas, o façam deixando a outros o papel antipático de pleitear a criação dos impostos necessários para cobrí-las; e evita também que as despesas não incluídas nos orçamentcs votados possam perturbar a regularidade financeira, gravando as responsabilidades do Tesourc." (5)

Todavia, devem ter pesado mais na decisão dos deputados que requereram a retirada da emenda, antes de sua votação, razões semelhantes às invocadas pelo Senador PAULO DE Frontin, ao iniciar-se a terceira discussão do projeto de reforma constitucional, no Senado:

“... a ser adotada essa providência (a criação ou aumento de despesa, simultâneamente com a da receita para custeá-la), não teríamos um só orçamento, teríamos uma série de receitas para caixas especiais, determinando extraordinárias complicações fiscais." (6)

Rejeitada, nesta parte, a terapêutica sugerida pelo Presidente BERNARDES, em 1924, para obviar os males resultantes das caudas orçamentárias, sòmente na Constituição de 1934 veio a prevalecer, incluído em Disposições

(5) Parecer da Comissão Especial da Câmara, in Anais da Revisão Constitucional, vol. p. 302-335.

(6) Discurso in Anais da Revisão Constitucional, vol. V, p. 770-782. 
Gerais, preceito expressamente contrário à cauda no sentido do volume da despesa:

"Art. 183. Nenhum encargo se criará ao Tesouro sem atrı. buição de recursos suficientes para lhe custear a despesa."

Além dêste preceito - que veio a desaparecer das Constituições posteriores, não obstante ser o que mais diretamente visava êsse aspecto da cauda orçamentária - a Lei Magna de 1934 introduziu, ainda, os seguintes dispo. sitivos com o mesmo fim:

"Art. 41, § 2." - Ressalvada a competência da Câmara dos Deputados e do Senado Federal, quanto aos respectivos serviços administrativos, pertence exclusivamente ao Presidente da República a iniciativa dos projetos de lei que aumentem vencimentos de funcionários, criem empregos em serviços já organizados, ou modifiquem, durante o prazo da sua vigência, a lei de fixação das fôrças armadas."

"Art. 50, $\S 2 .^{\circ}-\mathrm{O}$ orçamento dividir-se-á em duas partes, uma fixa e outra variável, não podendo a primeira ser alterada senão em virtude de lei anterior. A parte variável obedecerá a riga rosa especialização."

"Art. 186. O produto de impostos, taxas, ou quaisquer tributos criados para fins determinados não poderá ter aplicação diferente. Os saldos que apresentarem anualmente serão, no ano seguinte, inccrporados à respectiva receita, ficando extinta a tributação, apenas alcançado o fim pretendido."

A Constituição de 1937 foi mais radical, ainda, não admitindo como objeto de deliberação projetos ou emendas de iniciativa de qualquer das câmaras, desde que versassem sôbre matéria tributária ou que de uns ou de outras resultasse aumento de despesa (art. 64).

A Constituição vigente reproduz, neste particular, com outra redação e estendendo também aos tribunais a ressalva estabelecida para os serviços administrativos do Congresso (arts. $67, \S 2 .^{\circ}$; e $73, \S 2 .^{\circ}$ ), os dispositivos do texto constitucional de 1934, com exceção, como já foi dito, do que proibia a criação de encargo ao Tesouro sem atribuição de recursos suficientes para The custear a despesa, bem como do que regulava a aplicação do produto de impostos, taxas ou quaisquer tributos criados para fins determinados.

Quanto a êsse recuo da Constituição de 1946 em relação à de 1934, analisar-lhe os aspectos técnicos e práticos, nesta oportunidade, excederia o nosso modesto propósito de apenas apresentar um documento político-administrativo digno de registro.

Limitamo-nos, por conseguinte, a assinalar que se trata de uma questão em aberto, que poderia - com extraordinárias repercussões para as finanças públicas do país - ser reexaminada pelo Congresso Nacional, quer na revisão ccnstitucional ora em estudo, quer na votação de lei reguladora da elaboração orçamentária. 